\title{
Treating and Precepting with RESPECT: A Relational Model Addressing Race, Ethnicity, and Culture in Medical Training
}

\author{
Carol Mostow, LICSW', Julie Crosson, MD2,9, Sandra Gordon, MD ${ }^{3,9}$, Sheila Chapman, MD ${ }^{3,9}$, \\ Peter Gonzalez, $M D^{10,17}$, Eric Hardt, $M D^{6,9}$, Leyda Delgado, $M D^{3,8,9}$, Thea James, $M D^{7,9}$, \\ and Michele David, MD, MPH, MBA $3.4,5,9$
}

\begin{abstract}
'Department of Family Medicine, Boston Medical Center, Boston, MA, USA; ${ }^{2}$ Dorchester House Multi-Service Center, Dorchester, MA, USA; ${ }^{3}$ Department of Medicine, Section of General Internal Medicine, Boston Medical Center, Boston, MA, USA; ${ }^{4}$ Boston University Center for Excellence in Women's Health, Boston, MA, USA; ${ }^{5}$ Haitian Health Institute at Boston Medical Center, Boston, MA, USA; ${ }^{6}$ Department of Medicine, Section of Geriatrics, Boston Medical Center, Boston, MA, USA; ${ }^{7}$ Department of Emergency Medicine, Boston Medical Center, Boston, MA, USA; ${ }^{8}$ Latino Clinic, Boston Medical Center, Boston, MA, USA; ${ }^{\circ}$ Boston University School of Medicine, Boston, MA, USA; ${ }^{10}$ Harvard Medical School, Boston, MA, USA; "'Beth Israel Deaconess Medical Center, Boston, MA, USA.
\end{abstract}

BACKGROUND: In 2000 a diverse group of clinicians/ educators at an inner-city safety-net hospital identified relational skills to reduce disparities at the point of care.

DESCRIPTION: The resulting interviewing and precepting model helps build trust with patients as well as with learners. RESPECT adds attention to the relational dimension, addressing documented disparities in respect, empathy, power-sharing, and trust while incorporating prior cross-cultural models. Specific behavioral descriptions for each component make RESPECT a concrete, practical, integrated model for teaching patient care.

CONCLUSIONS: Precepting with RESPECT fosters a safe climate for residents to partner with faculty, address challenges with patients at risk, and improve outcomes.

KEY WORDS: health care disparities; cultural competency training; cross-cultural medicine; learning climate; physician-patient relationship; communication; professionalism.

J Gen Intern Med 25(Suppl 2): 146-54

DOI: $10.1007 / \mathrm{s} 11606-010-1274-4$

(c) Society of General Internal Medicine 2010

\section{INTRODUCTION}

The need to reduce health care disparities at the point of care raises urgent challenges for training of medical professionals. Each clinical encounter offers an opportunity to decrease risk for disparate care and poor outcomes. To succeed in this effort, clinicians must transform knowledge and awareness into action and skills; we must partner effectively with patients whose backgrounds may differ dramatically from our own. An expanding literature has identified patientcentered and culturally competent interpersonal skills as critical to maximizing patient satisfaction, trust, adherence, and outcomes. ${ }^{1}$ The challenges for clinical faculty are twofold. How do we establish the trust and safe learning climate trainees need to discuss openly their challenges in interactions with patients at risk for disparities? Secondly, if our learners do identify barriers to effective relationships with their patients, what skill set should we teach to help them be more effective? The well-documented decline in medical trainees' empathy during the clinical years means that house staff may be at particular risk for erosion of the interest and personal skills essential to maximize their patients' care $^{2,3}$. Attention to learning climate and supportive training relationships may help restore some of residents' empathy, while skills training remains important given the often pragmatic orientation of trainees and the need to sustain their motivation and self-efficacy.

In 2000 a racially and culturally diverse group of clinicianeducators at Boston Medical Center, a large urban safety net hospital, worked to address this training need, identifying the communication skills we use to relate effectively with our patients, a population with great diversity by race/ethnicity, culture, language, and class. We sought ways to address disparities within each individual doctor-patient encounter and new methods to teach these skills to busy trainees in clinical settings. The resulting RESPECT model is an integrated instrument for teaching, evaluation, and expansion of faculty skills. It provides a guide for what to do and how to teach it. By addressing relations with learners as well as patients, it offers help aligning the powerful hidden curriculum with the explicit curricular goals of compassionate patient care, sensitivity to diverse populations, interpersonal communication, professionalism, life-long learning, and
This article is dedicated with
Samuel Morse Putnam MD, MPH.

The RESPECT model was developed by members of the Diversity Curriculum Task Force in 2000 originally led by Carol Mostow, Peter Gonzalez, and Julie Crosson including Sandra Gordon, Sheila Chapman, Oranti Aladessamni, Thea James, Eric Hardt, Charles Brackett, and Sandhya Wahi. The model was further elaborated and implemented in the 2004-2005 faculty development project, which in addition to Mostow, Gordon and Crosson included Leyda Delgado, Michele David, Sondra Crosby, Danru Lee, and Sam Putnam. 
practice-based improvement. These are all core residency training requirements for accreditation by the American Council of Graduate Medical Education (ACGME) ${ }^{4}$.

\section{What is the RESPECT Model?}

The RESPECT model is an action-oriented set of communication and relational behaviors designed to build trust across differences of race/ethnicity, culture, and power ${ }^{5}$. Clinicians can use RESPECT to target documented disparities in doctorpatient relationships ${ }^{6}$. Medical educators can use the model as an integrated instrument for teaching, observation, and evaluation. Finally, preceptors can also apply the RESPECT model to their own relationships with learners to facilitate more effective training. The specific component skills for this interviewing model and educational framework are:

\section{Respect}

Explanatory model

Social context, including Stressors, Supports, Strengths and Spirituality

Power

Empathy

Concerns

Trust/ Therapeutic alliance/ Team.

See Table 1 for details on the use of RESPECT for patient care.

\section{Why Another Model?}

A review of the literature reveals important early contributions regarding how to elicit and negotiate differences of culture, health beliefs, and practices. Valuable attention to social context helps to understand some issues of the poor, but we did not find the same attention to matters regarding race, power, and distrust apparent to our racially/ethnically diverse patients and clinician group. We also noted that teaching models initially focused on the traditional information-gathering function of the interview rather than a relational guide addressing the affective domain. In the context of an emotional climate of potential distrust, racial, ethnic, and economic inequities, and risk for disparate outcomes, we were looking for a model that teaches physicians how to respond, not just what to ask. What should the physician do to build trust across differences of power, race, ethnicity, and class? Finally, we knew as preceptors that these issues felt sensitive and difficult to address in busy clinical settings with harassed residents trying to handle patients with challenging medical as well as social problems. What in the literature could help us build the relationships with residents that allowed these important conversations, so important to help them better meet the needs of the patients they serve?

A review of the literature on cross-cultural interviewing identified Kleinman's tool to elicit diverse health beliefs and practices. This widely used set of questions targets the patient's explanatory model, concerns about the illness, and goals of treatment ${ }^{7}$. Building on this work, Berlin and Fowkes proposed the LEARN Model, a framework for cross-cultural care $^{8}$. This model contributes the skills of Listening, Explanation of provider perceptions, Acknowledgement of differences, treatment Recommendations, and Negotiation of plans. The
ETHNIC mnemonic, designed by Levin et al., adds helpful attention to the way that cultural beliefs and practices may differ and be addressed. Model components include: seeking Explanations of the patients' understanding of illness; asking what Treatments patients use and expect; inquiring about alternative Healers; Negotiation of options incorporating patients' beliefs; designing culturally appropriate Interventions; and Collaboration with patients and their support systems ${ }^{9}$. Betancourt et al. developed the ESFT model, which added to the Explanatory model the expanded Social context of illness including economics, literacy, and other important constraints $^{10}$. This model also included attention to the patient's Fears and concerns about therapy and advocates Therapeutic contracting with patients around medication issues.

These valuable models all facilitate the gathering of relevant information related to cultural issues and introduce the skill of negotiation. However, they focus more on negotiating difference than addressing the power dynamics involved with differences of race, ethnicity, and class, or the relational and affective dimensions of the clinical encounter. These models do not themselves suggest or describe direct provider responsiveness to the emotional climate and potential distrust often operative in encounters across differences of race, ethnicity, and power in our society. ${ }^{11}$

Since 2001 additional cross-cultural interviewing models have been developed, including the BELIEF model by Dobbie et al., that do recognize the importance of addressing the affective domain in conversations across cultures. ${ }^{12}$ Its components are: health Beliefs, Explanation, Learn, Impact, Empathy, and Feelings. Still, little attention is given to the dynamics of power and historic oppression important for addressing differences of race, ethnicity, and class in contemporary America. According to a recent critique of multicultural education, too many cultural competence curriculae fail to provide direction in these dimensions. ${ }^{13}$

In 2008, scholars conversant with the literature regarding cultural competence and patient-centered communication called for the two fields to build on each others' contributions to increase effectiveness in both domains ${ }^{14}$. Teal and Street furthered this effort by publishing a comprehensive model using a complex array of communication skills. ${ }^{15}$ Their important work further supports the elements distilled and prioritized in the RESPECT model while suggesting curricular elements for an in-depth and intensive physician training process.

\section{Why RESPECT the Patient?}

Reduction of disparities in clinical practice requires strategic action to bridge differences of race/ethnicity, culture, and power. The RESPECT model can help medical professionals develop the practical skills needed to build trust actively. It expands on earlier models by adding the components of respect, empathy, and power specifically to target documented areas of disparity in interracial and cross-cultural encounters. ${ }^{16}$ In the context of inequity, stigma, and power differentials, proactive demonstrations of respect seek to mitigate patients' prior negative experiences and possible expectations of disrespect. ${ }^{17}$ In the RESPECT model, the provider actively conveys empathy to the patient rather than simply collecting data. Since so much of trust-building is affective and relation- 
Table 1. How (and why) to RESPECT the Patient

\begin{tabular}{|c|c|c|c|c|}
\hline Skill & Definition & Behavioral description & Examples & Relevant evidence \\
\hline Respect: show & $\begin{array}{l}\text { A demonstrable attitude } \\
\text { communicating the value } \\
\text { and autonomy of the } \\
\text { patient and the validity } \\
\text { of his/her concerns }\end{array}$ & $\begin{array}{l}\text { Non-verbal: Maintain attentive } \\
\text { posture, appropriate eye and } \\
\text { personal contact; follow cues } \\
\text { regarding personal space, } \\
\text { physical contact, and } \\
\text { appropriate greetings } \\
\text { Verbal: Welcome patient to } \\
\text { encounter; introduce self and } \\
\text { explain role on team; ask the } \\
\text { patient how they want to be } \\
\text { addressed; recognize and } \\
\text { affirm strengths and efforts }\end{array}$ & $\begin{array}{l}\text { "What would you like } \\
\text { me to call you?" } \\
\text { "You overcame a lot to } \\
\text { get here today!" }\end{array}$ & $\begin{array}{l}\text { Disparity: African American, } \\
\text { Hispanic, and Asian patients } \\
\text { reported feeling less respected } \\
\text { by their doctors than did } \\
\text { White patients }^{17}\end{array}$ \\
\hline $\begin{array}{l}\text { Expanatory } \\
\text { model: ask }\end{array}$ & $\begin{array}{l}\text { The patient's understanding } \\
\text { of what causes their illness, } \\
\text { or what will help it }\end{array}$ & $\begin{array}{l}\text { Non-verbal: Give patient space } \\
\text { to share their ideas by } \\
\text { listening without judgment } \\
\text { Verbal: Ask patient what they } \\
\text { think is causing or will } \\
\text { alleviate their symptoms }\end{array}$ & $\begin{array}{l}\text { "What do you or your } \\
\text { family think is causing } \\
\text { your symptoms?" } \\
\text { "Why do you think this started } \\
\text { when it did?" "What do you } \\
\text { think will solve the problem?" }\end{array}$ & $\begin{array}{l}\text { Patients and doctors often have } \\
\text { different ideas that remain } \\
\text { unexplored unless elicited. } \\
\text { Without discussion, patients } \\
\text { leave less satisfied }^{20}\end{array}$ \\
\hline $\begin{array}{l}\text { Social } \\
\text { context: ask }\end{array}$ & $\begin{array}{l}\text { Impact of patient's life upon } \\
\text { illness and of illness on his/ } \\
\text { her life. Include stressors, } \\
\text { supports, strengths, } \\
\text { spiritual resources that } \\
\text { influence patient, } \\
\text { health or care }\end{array}$ & $\begin{array}{l}\text { Nonverbal: Show interest } \\
\text { and pay attention } \\
\text { Verbal: Ask how patient's } \\
\text { illness affects their life and } \\
\text { how their life affects illness }\end{array}$ & $\begin{array}{l}\text { "What should I know about } \\
\text { you to care for you best?" } \\
\text { "What is hardest for you?" } \\
\text { "Who helps you the most?" } \\
\text { "What keeps you going?" } \\
\text { "What about religion?" }\end{array}$ & $\begin{array}{l}\text { Low social support predicts } \\
\text { higher mortality post MI }{ }^{21} \\
\text { Negative health consequences } \\
\text { follow death of spouse alleviated } \\
\text { by presence of confiding figure }\end{array}$ \\
\hline \multirow[t]{2}{*}{ Power: share } & $\begin{array}{l}\text { Access to status, control, } \\
\text { resources, options, } \\
\text { and ability to produce } \\
\text { desired outcomes }\end{array}$ & $\begin{array}{l}\text { Non-verbal: Reduce physical } \\
\text { barriers. Don't dominate } \\
\text { the interaction. Sit }\end{array}$ & $\begin{array}{l}\text { "Beside your diabetes, what } \\
\text { else should we talk about?" } \\
\text { "What would make your } \\
\text { medications easier?" }\end{array}$ & $\begin{array}{l}\text { Disparity: White physicians } \\
\text { dominate conversation more } \\
\text { with non-white patients }{ }^{36}\end{array}$ \\
\hline & $\begin{array}{l}\text { Power gradient } \\
\text { favors doctors }^{11}\end{array}$ & $\begin{array}{l}\text { Verbal: Listen. Limit } \\
\text { interruptions. Build history } \\
\text { rather than take it. }{ }^{24} \text { Use } \\
\text { EMR to share information } \\
\text { with patient via graphs, etc. } \\
\text { Invite open discussion of } \\
\text { disagreement. Negotiate } \\
\text { agenda/treatment plan } \\
\text { by eliciting preferences. } \\
\text { Empower patient, } \\
\text { recognize strengths }\end{array}$ & $\begin{array}{l}\text { "Thanks for telling me that } \\
\text { you don"t agree. What } \\
\text { do you think?" }\end{array}$ & $\begin{array}{l}\text { Self-efficacy needed to } \\
\text { make healthy choices }\end{array}$ \\
\hline Empathy: show & $\begin{array}{l}\text { Verbal and nonverbal } \\
\text { responses that validate } \\
\text { patients' emotions and } \\
\text { cause them to } \\
\text { feel understood. }\end{array}$ & $\begin{array}{l}\text { Non-verbal: Listen attentively } \\
\text { and respond accordingly } \\
\text { Verbal: Name and validate } \\
\text { patients' emotions. Put } \\
\text { significance of patient's } \\
\text { experience into words to } \\
\text { convey specific } \\
\text { understanding }\end{array}$ & $\begin{array}{l}\text { "That must be hard, anyone } \\
\text { would feel that way." "This } \\
\text { can be scary. Let's talk } \\
\text { about it." "The injury } \\
\text { changed everything for you" }\end{array}$ & $\begin{array}{l}\text { Disparity: Doctors display } \\
\text { less warmth with } \\
\text { African-American patients }{ }^{36}\end{array}$ \\
\hline $\begin{array}{l}\text { Concerns / } \\
\text { fears: ask }\end{array}$ & $\begin{array}{l}\text { Worries about symptoms, } \\
\text { diagnosis, or treatment, } \\
\text { often unexpressed }\end{array}$ & $\begin{array}{l}\text { Nonverbal: Head nods, etc., } \\
\text { to encourage patient to } \\
\text { give details } \\
\text { Verbal: Ask open-ended } \\
\text { questions about } \\
\text { fears/concerns }\end{array}$ & $\begin{array}{l}\text { "What worries you the } \\
\text { most?" "What scares } \\
\text { you about the medication?" } \\
\text { "Are you worried about } \\
\text { sex after your heart attack?" }\end{array}$ & $\begin{array}{l}\text { Unvoiced concerns lead to } \\
\text { unmet needs and patient } \\
\text { dissatisfaction }^{25}\end{array}$ \\
\hline $\begin{array}{l}\text { Trust/team- } \\
\text { building/ } \\
\text { therapeutic } \\
\text { alliance }\end{array}$ & $\begin{array}{l}\text { Relationship built on } \\
\text { understanding, power- } \\
\text { sharing and empathy; } \\
\text { patient confident that } \\
\text { doctor acts on his behalf }\end{array}$ & $\begin{array}{l}\text { Trust: Notice/respond to } \\
\text { signs of distrust. } \\
\text { Elicit and respond to } \\
\text { expectations. Reassure } \\
\text { and clarify follow-up. } \\
\text { Follow through }\end{array}$ & $\begin{array}{l}\text { "People in my family have had } \\
\text { the same thing." "Should we } \\
\text { get your family involved to } \\
\text { help us?" "We"re here when } \\
\text { you need us." "Let's make } \\
\text { sure we answer all your }\end{array}$ & $\begin{array}{l}\text { Disparity: } 62.8 \% \text { Blacks vs. } \\
38.4 \% \text { Whites believe their } \\
\text { doctors have or would } \\
\text { experiment on them } \\
\text { without their consent. }^{26} \\
\text { Black patients receive }\end{array}$ \\
\hline $\begin{array}{l}\text { Build: don't } \\
\text { assume }\end{array}$ & & $\begin{array}{l}\text { Therapeutic alliance: } \\
\text { Find specific common } \\
\text { goals, negotiate differences } \\
\text { Team building: Identify, } \\
\text { enlist, and collaborate with } \\
\text { potential members } \\
\text { of health care team }\end{array}$ & $\begin{array}{l}\text { questions so you feel } \\
\text { comfortable making } \\
\text { your decision" }\end{array}$ & $\begin{array}{l}\text { less support, partnering } \\
\text { and information }{ }^{27}\end{array}$ \\
\hline
\end{tabular}


al, these empathic skills are particularly important. ${ }^{18,19}$ Providers need skills to counterbalance power differentials through verbal and nonverbal behaviors, actively seeking patients' concerns, potential disagreements, and barriers to treatment.

Accumulating evidence supports the validity of the RESPECT components as critically related to disparities in care (see Table 1: refs ${ }^{16,20-27,36}$ ). For example, disparities were identified in patients' experience of respect and trust in surveys of patients and providers conducted by the Kaiser Family Foundation and the Commonwealth Fund. ${ }^{17,28-34}$ Trust in doctors among African-American patients continues to be diminished by the legacy of the Tuskegee experiment, often reinforced by more contemporary racial experiences. ${ }^{35,36}$ The components of power and empathy are also supported by evidence regarding disparate experiences of non-white patients. White physicians dominate speech more with nonwhite patients and display less warmth and patient-centered behaviors. ${ }^{16,36}$ Another study documented that black patients received less support, partnering, and information from their doctors and have lower levels of trust in their physicians. ${ }^{27}$

Collaborative empowerment and empathy assume even greater importance given recent findings that physician dominance reduced patient engagement while demonstrations of caring elicited more emotional sharing by the patient and increased activation in the interview ${ }^{37}$. Another study found that the majority of patients do have the explanatory models of illness described by Kleinman as so pivotal in health-related behaviors, but did not disclose them unless specifically invited to share them. ${ }^{20}$

The contribution of social factors to health and patients' approach to health care has also been well established. ${ }^{38}$ The RESPECT model offers a helpful tool to focus quickly and prioritize elements of the social context most salient to the patient. Physicians can focus on matters of greatest importance to the patient rather than squandering time on less relevant closed-ended demographic information. (see Table 1). The value of identifying the patient's stressors is supported by clinical studies. ${ }^{39,40}$ By eliciting strengths, supports, and spiritual resources as well as stressors, the RESPECT model replaces a focus on social deficits with an appreciation of the internal, family, and community strengths fostering selfefficacy, a critical element for health behavior change. ${ }^{23}$ Recent literature on patient-centered approaches suggests that prompt attention to patients' emotions and perspective may add to, not diminish efficiency. ${ }^{41}$

\section{Why RESPECT the Trainee?}

Recognizing the learning climate and working to improve teaching relationships addresses the implicit "hidden curriculum" within medical education. ${ }^{42-44}$. Much learning occurs by selective reinforcement of behaviors that may not be consciously examined. ${ }^{45}$ Effective teaching must address the persisting decline in empathy documented during the clinical years of medical school and residency. ${ }^{2,3,46}$ Caring for the socially disadvantaged adds to the personal stressors of residency training. ${ }^{47}$ Explorations of residents' errors suggest a reluctance to discuss them with faculty. ${ }^{48}$ The Institute of Medicine reports on patient safety indicate that rigid hierarchies and atmospheres of fault-finding and blame are antithetical to a safe culture for patient care. A "flattened hierarchy" promotes honesty and reduces defensiveness. ${ }^{49}$ Growing attention to the implicit curriculum suggests the importance of using methods to train residents that are congruent with learning objectives and content. ${ }^{50,51}$

Our explicit application of the RESPECT model to both patients and learners is similar to an innovative contribution by Kern et al. teaching residents an approach to psychosocially sensitive care of patients while applying the same approach to the residents. ${ }^{52}$ As they note, empathic listening skills may wither in residents whose own concerns are routinely ignored. A similar call to address power dynamics in the teaching of prospective doctors recently came from educators focused on the elimination of health disparities. ${ }^{13}$ We must create a safe learning climate for the open dialogue that learners need to internalize professional values and commit to social justice goals. The call for a wholesale "reorientation of the traditional teacher-student paradigms" requires faculty development related to these new teaching methods.

\section{RESPECT: A Versatile Teaching Tool}

Ten years using RESPECT has persuaded us that it is an effective model promoting generalizable skills for a wide range of health care providers working in varied clinical settings. In addition to its utility in clinical practice, the RESPECT model has proven to be a versatile tool for teaching, evaluation, and faculty development.

For pre-clinical learners, didactic presentations and experiential approaches provide exposure to the relational process of clinical care. We adapted RESPECT as an observational tool for students to observe their attendings at work with patients (Looking for RESPECT, BOX 1). Following a lecture introducing the framework and an exercise about difference and power, all first year medical students at Boston University School of Medicine use the tool in their first patient contacts as they observe faculty in diverse clinical settings. They use Looking for RESPECT to guide their observations and write-ups of physician-patient encounters with a focus on patient concerns and relational elements beyond the classical data-oriented approach. Through the lens of the model, students see the clinical relationship and watch doctors build trust and understanding across differences. 


\section{Looking for RESPECT:}

\section{An observation exercise or assessment tool for demonstrating ACGME competencies}

The RESPECT model conveys a value essential to clinical practice and required for all effective communication.

It also offers a handy list of essential components to optimize health care encounters for both patient and physician, especially important when facing additional differences of culture, race, ethnicity, class, etc. between the parties.

What did the doctor learn about the patient's Explanatory model of the illness and ideas of what might help? (e.g. what's wrong with me? what do I think will make me better?)

What did the doctor learn about the Social context of the patient including Stressors, Supports, Strengths, Spiritual beliefs and practices which might affect health, treatment, expectations, or relationships with the doctor and healthcare system? How does the patient's life affect his illness? How does his illness affect his life?

What expectations and preferences did the patient and doctor each seem to have for the Power relationship? Notice both non-verbal and verbal cues. Pay attention to displays of deference, control, hierarchy. Who does the talking? Who determines the agenda ? What did the doctor or patient do or say during the encounter which seemed to empower or disempower either party? Does the doctor seek the patient's input and preferences or simply announce to the patient what will happen?

What opportunities were there for the doctor to convey Empathy? What did the doctor do or say to which conveyed an understanding of the patient's experience and its significance to the patient? What were the patient's responses?

Are there any Concerns and fears which underlie or coexist with the patient's presenting problems?

C What prompted the patient to share these? What did the physician do to elicit or facilitate this fuller, possibly more emotional disclosure?

What seemed to be the patient's initial level of Trust? What did the doctor say or do during the interview which seemed to modify the patient's level of Trust? What verbal and non-verbal indicators did you notice? Was a Therapeutic plan created? Did the doctor and patient reach common ground regarding the problem and the approach to diagnosis and treatment? Are there any indications that there might be obstacles to and/or disagreements about the next steps? If there remained divergent preferences at the end of the interview, was the doctor able to negotiate a partnership based on other shared goals?

\section{NOTE: Make sure to observe non-verbal as well as verbal behaviors regarding the above.}

To teach these concepts to residents and practicing clinicians, we use case-based learning in discussions, role plays, and trigger tapes. This approach has worked well in interactive didactic presentations with medical residents and clinicians in a variety of settings. As the model is easily generalized, faculty have used it to train substance abuse screeners and health care workers providing breast cancer outreach. ${ }^{53}$ It has also been adopted for the didactics, discussion, and video demonstration for Alcohol Clinical Teaching, a web-based alcohol training program. ${ }^{54}$ In a training for experienced eye care professionals and faculty, we solicited problematic crosscultural clinical encounters cases and addressed them using RESPECT-based role play. ${ }^{55}$

For residents, we use an inductive exercise designed to help them discover the RESPECT model actively. In case-based preclinic conferences at continuity clinics, we encourage them to think through their own cases with challenging communication issues. They then identify the elements contributing to a past success bridging differences and distrust, which combine to form the RESPECT model. The residents then reflect and strategize with peers and faculty about how to apply the model to their other challenging cases, identify skills and behaviors to try in future encounters.

We have found the observation tool designed for medical students, Looking for RESPECT (BOX 1), to be equally useful for preceptors in resident primary care clinics. The model provides a framework that helps faculty go beyond evaluation of standard bedside skills to assess critical competencies of interpersonal communication and professionalism including sensitivity to the needs of diverse populations ${ }^{4}$. We can use the same teaching tool to stimulate residents' reflections and selfassessments as well as for more structured performance evaluation as has been suggested. ${ }^{56}$

Effective teaching in this area requires that residents disclose the challenges that they face in order to reflect on what they're doing and consider new approaches. A top-down approach is unlikely to succeed in promoting development of this level of 'critical consciousness. ${ }^{13}$ Simply telling learners to be culturally 
sensitive and respectful does not assure that they can and will do so. We realized that we needed to apply the RESPECT model skills to build relationships with our learners as well as with our patients. We have translated those skills into a precepting guide that helps faculty improve their skills. By explicitly addressing issues of power, Precepting with RESPECT (BOX 2) addresses the implicit curriculum and harnesses parallels between educational and clinical encounters. ${ }^{52}$ The model incorporates relational and cognitive elements from recommended precepting models that elicit the resident's model of understanding, encourage independent thinking, and facilitate targeted educational interventions. ${ }^{57,58}$

\section{Precepting with RESPECT:}

\section{Application of the RESPECT model to preceptor-learner relationships}

RESPECT

\section{EXPLANATORY MODEL}

SOCIAL CONTEXT

POWER

EMPATHY

CONCERNS
Approach the learner with respect.

Builds resident confidence, preceptor resident relationship. Reduces defensiveness. "I know how hard you've been working to try and get his diabetes under control".

Elicit the resident's thoughts about the patient and interest in the patient's perspective. Helps preceptor learn what resident knows and has asked as starting point for further discussion. Conveys interest in resident's perspective while supporting resident's interest in patient's perspective

"What do you think is going on with the patient?" "What does patient think is causing his symptoms?"

Check re residents' well-being and context . Explore possible professional and personal stressors.

Builds preceptor-trainee relationship. Models how to act with patients.

"How are things going for you these days?" "What clinical rotation are you on?"

Find ways to share power and support resident self-efficacy. Resist the temptation to take over in the face of learner's uncertainty.

Helps assess clinical judgment, build problem-solving ability and increase investment in solution.

"How might you find out why this patient has a hard time taking his medicines daily?"

Let resident know their frustrations and emotions are heard

Documented decline in residents' mood and empathy for patients as well as differences from their patients' background make this step essential. Faculty support may enable residents to engage more effectively with patient.

"After all your effort, I can imagine how frustrating it is that she didn't fill her prescription."

"Particularly when I'm tired, it can be hard to put aside my own frustration to find out what's going on from the patient's perspective."

Elicit and address residents' concerns about situations they don't feel confident handling or fear will make visit too long.

Help residents strategize about possible solutions and educate about relevant data

Replaces anxiety with information to improve quality and efficiency

"I know you were worried about eliciting more of the patient's concerns but eliciting them doesn't mean you or the patient can tackle them all in one visit."

"Let's discuss how to identify your and the patient's top priorities, come up with a plan for today and bring him back for follow-up and to address the other issues."

Building on all the skills above fosters trust in the preceptor-resident relationship. Learners may become more willing to identify areas of challenge.

"I admire your openness and ability to share with me that your patient was so frustrated that she wanted to change doctors." "How can I help you?" 
We discovered some of these approaches during a year-long faculty development project at our institution in 2004-2005, funded by BCBS of Massachusetts Medical Foundation. ${ }^{59}$ We applied the RESPECT model in resident clinics and other settings. We sought to make cultural competence, prevention of health care communication disparities, and more effective relationships between residents and patients a routine part of precepting and clinical care. Faculty sought increased comfort and effectiveness precepting residents to connect more effectively with their diverse patient population. A group of ten experienced clinician-educators of diverse racial/ethnic backgrounds joined together in monthly 3-h sessions. The faculty group included four blacks, four whites, one Asian, and one Latina; four participants were born outside of the USA. Participants included clinic preceptors, in-patient attendings, an emergency room attending, and a medical educator, all involved with resident and/or medical student teaching. Most of them had participated in the ongoing Diversity Curriculum Task Force that had originally developed the RESPECT model. Despite our extensive experience, like our learners, we needed the opportunity to reflect and develop skills on how best to approach sensitive subjects and resident interactions that made us uncomfortable. While our commitment to the goals of cultural competence was clear, how to be most effective with our learners in getting there was not. Using Looking for RESPECT (BOX 1), preceptors identified residents' learning needs and then designed interventions for individual residents using Precepting with RESPECT (BOX 2). Preceptors often role-played these interactions to practice and get feedback from other faculty using faculty development strategies developed by the American Academy on Communication in Healthcare. ${ }^{60}$ This protected learning environment allowed us to experiment with teaching methods, strategize about challenging teaching encounters, and share resulting observations of resident behaviors and attitudes.

\section{Evaluation}

In an effort to test, refine, and disseminate our RESPECT model into the clinical setting, we developed a self-administered questionnaire to evaluate its impact on teachers and trainees. In 2004-2005, we surveyed a diverse group of internal medicine residents at our hospital before and after implementing the RESPECT model as a teaching tool in resident primary care clinic sessions. Ten precepting faculty underwent structured interviews at the end of the intervention. Forty-four residents completed the baseline questionnaire and 20 the post-intervention questionnaire.

The ten precepting faculty all reported increased comfort and skill precepting regarding cross-cultural care in resident continuity clinics. In particular, some expressed a willingness to address racial issues affecting patient care that they had previously regarded as "taboo." Another theme noted was that faculty members also improved their own interviewing skills. Among the residents surveyed, 88\% felt that the RESPECTbased training was useful. We found differences in several survey items pre- and post-training. Residents reported greater comfort when interacting with diverse groups (60\% pre, $80 \%$ post). Residents seemed more convinced that cross-cultural training might improve health care delivery (57\% pre, 93\% post). Some reported major improvement in skills related to culturally sensitive interviewing ( $10 \%$ pre, $20 \%$ post). The number of residents reporting no skills in this area declined
(12\% pre, 0\% post). Small numbers and limited response rates precluded more statistical analysis of survey results. Changes in preceptor and resident schedules along with variation in the frequency of contact also limited the data.

\section{DISCUSSION}

The RESPECT model was a product of a highly diverse group of clinician-educators working together for 10 years at a large urban medical center that cares for racially and ethnically diverse patients from the US and abroad. It is notable that diversity of the faculty group itself allowed us to draw upon personal and clinical experience and to share insights about the role of differences and of race in particular. Together we were able to derive a model of broad clinical utility to the care of our patients. A diverse faculty group's access to clinical and personal experience outside of majority culture may foster insights less apparent to others ${ }^{28,62}$. However, in the 20042005 evaluation of the project to improve faculty participants' teaching skills by precepting with RESPECT, our faculty preceptors also noted with interest improved interactions with their own patients by using the RESPECT model. The relational elements in the RESPECT model for interviewing and teaching have a lot to offer even a very sophisticated faculty and remind us that cultural competence and relationship-centered care of at-risk populations require ongoing efforts.

The RESPECT model can be useful to medical schools, residencies, and other health care organizations in meeting their training goals, core curricular competencies, and patient care standards, assuring that quality care is delivered equitably to all. To monitor and continually improve the quality of care and communication with all patients, evolving definitions by the ACGME ${ }^{4}$ and others ${ }^{44,63-65}$ of professionalism, practice-based improvement, and systems-based practice remind us that faculty and residents alike need to be lifelong learners. We must remain ever mindful of our ongoing impact on others and the value of teaming up with our patients, trainees, and colleagues. Respectful communication across power differentials among faculty, residents, and colleagues promotes positive professional communication and teamwork along with full and open disclosure. ${ }^{49}$ This change of culture can promote a personal and systems-based examination of obstacles to optimum care and patient safety, especially important for patients at risk for poor outcomes.

One of the limitations of the RESPECT evaluation is that because of small resident numbers in the pilot clinics and the large number of them unavailable to complete the postintervention survey, we could not perform tests of statistical difference. However, to date one study of the efficacy of the teaching model has been published. ${ }^{55}$ Cultural competence training based on the RESPECT model was conducted for faculty at The New England Eye Institute and New England College of Optometry. A follow-up study demonstrated measurable positive impact that persisted 3 months post-intervention, using a cultural competency scale validated by Campinha-Bacote. ${ }^{61}$

It has been 10 years since we initially derived our interviewing and teaching model from the insights of our racially, ethnically diverse group of clinician educators. During that time empirical data as well as consensus recommendations 
from the fields of patient-centered communication and cultural competence have been published that support the elements in our model. ${ }^{1,6,15,16}$ For patients already at risk for disparities, a doctor who dominates the encounter or withholds warmth or empathy is a threat and a lost opportunity to partner for better health. ${ }^{5,6,36}$ By addressing barriers to trust posed by power differentials, RESPECT may be a helpful part of the solution. What we offer is an easily remembered mnemonic that prioritizes elements linked to documented disparities in a clear, readily applied model. Attention to the power dynamics within our own relationships with residents has helped us precept our learners with RESPECT. Designed to improve communication with patients at risk for disparities, the RESPECT model provides a flexible, practical, and widely applicable teaching model targeting documented disparities in health care communication while promoting relational skills needed to build trust and partner for better health care.

Acknowledgements: This work was supported in part by grants from the Kenneth B. Schwartz Center and by Blue Cross Blue Shield of Massachusetts Medical Foundation. We would also like to acknowledge the value to our work of Elaine Pinderhughes' attention to power and race (Understanding Race, Empathy and Power 1989), the focus on patient and relationship-centered care by the American Academy on Communication in Healthcare (formerly AAPP), and the LEARN and ESFT models cited below. Aileen Richmond, MPH, provided valuable assistance with data collection, faculty interviews, and collation of themes. We also thank Beth Lown, MD, for kindly reviewing the manuscript.

Conflict of Interest: None disclosed.

Corresponding Author: Carol Mostow, LICSW; Department of Family Medicine, Boston Medical Center, 771 Albany Street, Dowling 5, Boston, MA 02118, USA (e-mail: Carol.Mostow@bmc.org).

\section{REFERENCES}

1. Fuertes JN, Boylan LS, Fontanella JA. Behavioral indices in medica care outcome: the working alliance, adherence and related factors. JGIM. 2009;24(1):80-5.

2. Bellini LM, Baime M, Shea JA. Variation of mood and empathy during internship. JAMA. 2002;287(23):3143-6

3. Bellini LM, Shea JA. Mood change and empathy decline persist during 3 years of internal medicine training. Acad Med. 2005;80(2):164-7.

4. ACGME competencies Available at: http://www.acgme.org/outcome/ Comp/compFull.asp Accessed January 2010.

5. Bigby JA, ed. Cross-Cultural Medicine. Philadelphia, PA: American College of Physicians; 2003. Chapter One: Beyond Culture: Strategies for Caring for Patients from Diverse Racial, Ethnic, and Cultural Groups. pp 20-21

6. Smedley BD, Stith AY, Nelson AR, eds. Unequal Treatment: Confront ing Racial and Ethnic Disparities in Health Care. Washington, DC National Academy Press; 2002. Chapter 4: Assessing Potential Sources of Racial and Ethnic Disparities in Care: The Clinical Encounter.

7. Kleinman A, Eisenberg L, Good B. Culture, illness, and care: clinical lessons from anthropologic and cross-cultural research. Ann Intern Med. 1978;88(2):251-8.

8. Berlin EA, Fowkes WC. A teaching framework for cross-cultural health care: application in family practice. West J Med. 1983;139(6):934-8.

9. Levin S, Like R, Gottlieb J. ETHNIC: a framework for culturally competent clinical practice. In Appendix: useful clinical interviewing mnemonics. Patient Care. 2000;34(9):188-9.

10. Betancourt J, Carrillo J, Green A. Hypertension in multicultural and minority populations: linking communication to compliance. Curr Hypertens Rep. 1999; 1(6):482-8

11. Pinderhughes E. Understanding Race, Ethnicity and Power: The Key to Efficacy in Clinical Practice. New York: Free Press; 1989.
12. Dobbie A, Medrano M, Tysinger J, et al. The BELIEF instrument: a preclinical teaching tool to elicit patients' health beliefs. Fam Med. 2003;35(5):316-9.

13. Kumagai AK, Lypson ML. Beyond cultural competence: critical consciousness, social justice, and multicultural education. Acad Med. 2009;84(6):782-7.

14. Saha S, Beach MC, Cooper L. Patient centeredness, cultural competence and healthcare quality. J Nat Med Assoc. 2008;100(11): 1275.

15. Teal CR, Street RL. Critical elements of culturally competent communication in the medical encounter: a review and model. Soc Sci Med. 2009;68:533-43.

16. Cooper L, Roter DL. Patient-provider communication: the effect of race and ethnicity on process and outcomes of healthcare in Unequal Treatment: Confronting Racial and Ethnic Disparities in Healthcare. Smedly BC, Stith AY, Nelson AR, eds. Institute of Medicine. 2002:55293

17. The Commonwealth Fund 2001 Health Care Quality Survey. [cited 2009; Available at: http://www.commonwealthfund.org/Content/Surveys/ 2001/2001-Health-Care-Quality-Survey.aspx. Accessed January 2010.

18. Neeraj KA, Gustafson DH. Perceived helpfulness of physicians' communication behavior and breast cancer patients' level of trust over time. J Clin Oncol. 2009;24(2):252-5.

19. Washington D, Bowles J, Saha S, et al. Transforming clinical practice to eliminate racial and ethnic disparities in health care. JGIM. 2008;23 (5):685-91.

20. Lang F, Floyd MR, Beine KL, et al. Sequenced questioning to elicit the patient's perspective on illness: effects on information disclosure, patient satisfaction, and time expenditure. Fam Med. 2002;34(5):325-30.

21. Mookadam F, Arthur HM. Social support and its relationship to morbidity and mortality after acute myocardial infarction: systematic overview. Arch Intern Med. 2004;164(14):1514-8.

22. Pennebaker J, O'Hearn R. Confidants' feedback and traumatic life events. J Trauma Stress. 1995;8(1).

23. DiClemente C, Prochaska J, Gibertini M. Self-efficacy and the stages of self-change of smoking. Cogn Ther Res. 1985;9(2).

24. Haidet P, Paterniti DA. "Building" a history rather than "taking" one: a perspective on information sharing during the medical interview. Arch Intern Med. 2003;163(10): 1134-40.

25. Dyche L, Swiderski D. The effect of physician solicitation approaches on ability to identify patient concerns. J Gen Intern Med. 2005;20(3):26770 .

26. Corbie-Smith G, Thomas SB, St. George DMM. Distrust, race, and research. Arch Intern Med. 2002;162(21):2458-63.

27. Gordon HS, Street RL Jr, Sharf FM, et al. Racial differences in trust and lung cancer patients' perceptions of physician comunication. J Cln Oncol. 2006;24(6):904-9.

28. The Kaiser Family Foundation National Survey of Physicians Part 1: Doctors on Disparities in Medical Care. March 2002 http://www.kff.org/ minorityhealth/20020321a-index.cfm Accessed January 2010.

29. Cooper LA, Roter DL, Johnson RL, et al. Patient-centered communication, ratings of care, and concordance of patient and physician race. Ann Int Med. 2003;139(11):907-15

30. Blanchard J, Nayar S, Lurie $\mathbf{N}$. Patient-provider and patient-staff racial concordance and perceptions of mistreatment in the health care setting. JGIM. 2007;22(8):1184-9.

31. Casagrande SS, Gary TL, LaVeist DJ, et al. Perceived discrimination and adherence to medical care in a racially integrated community. JGIM. 2007;22(3):389-95.

32. Boulware LE, Cooper LA, Ratner LE, et al. Race and trust in the health care system. Public Health Rep. 2003;118(4):358-65.

33. Cooper LA, Beach MC, Johnson RL, et al. Delving below the surface. Understanding how race and ethnicity influence relationships in health care. JGIM. 2006;21(Suppl 1):S21-7.

34. Blanchard J, Lurie N. R-E-S-P-E-C-T: patient reports of disrespect in the health care setting and its impact on care. J Fam Pract. 2004;53 (9):721-30.

35. Corbie-Smith G. The continuing legacy of the Tuskegee Syphilis Study: considerations for clinical investigation. Am J Med Sci. 1999;317(1):5-8.

36. Johnson RL, Roter D, Powe NR, et al. Patient race/ethnicity and quality of patient-physician communication during medical visits. Am J Publ Health. 2004;94(12):2084-90.

37. Mast MS, Hall JA, Roter DL. Caring and dominance affect participants' perceptions and behaviors during a virtual medical visit. JGIM. 2008;23 (5):523-7. 
38. Green AR, Betancourt JR, Carrillo JE. Integrating social factors into cross-cultural medical education. Acad Med. 2002;77(3):193-7.

39. Spiegel D. Healing words: emotional expression and disease outcome. JAMA. 1999;281(14):1328-9.

40. Smyth JM, Stone AA, Hurewietz A, Kaell A. Effects of writing about stressful experiences on symptom reduction in patients with asthma or rheumatoid arthritis: a randomized trial. JAMA. 1999;281(14):1304-9.

41. Mauksch LB, Dugdale D, Dodson S, Epstein R. Relationship, communication and efficiency in the medical encounter: creating a clinical model from a literature review. Arch Intern Med. 2008;168(13):1387-95.

42. Hafferty FW. Beyond curriculum reform: confronting medicine's hidden curriculum. Acad Med. 1998;74(3):403-7.

43. Hafferty FW, Frank R. The hidden curriculum, ethics teaching, and the structure of medical education. Acad Med. 1994;69(11):861-71.

44. Braddock CH, Eckstrom E, Haidet P. The "New Revolution" in medical education: fostering professionalism and patient-centered communication in the contemporary environment. JGIM 2004;19(5 part 2):610-11.

45. Murray-Garcia JL, Garcia J. The institutional context of multicultural education: what is your institutional curriculum? Acad Med. 2008;83 (7):646-66.

46. Hojat M, Vergare MJ, Maxwell K, Brainard G, Herrine SK, Isenberg GA, Veloski J, Gonnella JS. The devil is in the third year: a longitudinal study of erosion of empathy in medical school. Academic Medicine. 2009;84(9): 1182-1191.

47. Lurie N, Yergan J. Teaching residents to care for vulnerable populations in the out-patient setting. JGIM. 1990;5:527-34.

48. Bosk CL. Forgive and Remember: Managing Medical Failure. 2nd ed Chicago: University of Chicago Press; 2003.

49. Kohn LT, Corrigan JM, Donaldson MS, eds. To Err is Human: Building A Safer Health System. Committee on Quality of Health Care in America, Institute of Medicine; 1999.

50. Branch WT Jr, Kern D, Haidet P, et al. Teaching the human dimensions of care in clinical settings. JAMA. 2001;286(9):1067-74.

51. Haidet $\mathbf{P}$, Stein $\mathbf{H}$. The role of the student-teacher relationship in the formation of physicians. JGIM. 2006;21(S1):S16-S20.
52. Kern DE, Branch WT Jr, Jackson JL, Brady BW, Feldman MD, Levinson W, Lipkin M Jr. Teaching the psychosocial aspects of care in the clinical setting: practical recommendations. Acad Med. 2005;80(1):8-20

53. Bigby J, Ko LK, Johnson N, David MM, Ferrer B, REACH Boston 2010. Breast and cervical cancer coalition: a community approach to addressing excess breast and cervical cancer mortality among women of African descent in Boston. Public Health Reports. 2003;118(4):334.

54. Saitz R, et al. Alcohol Clinical Training Project, Implementation and evaluation report. supported by the National Institute on Alcohol Abuse and Alcoholism (NIAAA) R25 AA013822, www.alcoholtraining.org, July,2007:25-9.

55. Denial A, Hoppe E, Carlson N. Assessing cultural competence in optometric faculty. Optom Educ. 2006;92-5

56. Assessing competence in communication and interpersonal skills: The Kalamazoo II Report. Acad Med. 2004;79:495-507.

57. Parrot S, et al. Evidence-based office teaching: the five-step microskills model of clinical teaching. Fam Med. 2006;38(3):164-7.

58. Neher J. A five-step "microskills" model of clinical teaching. J Am Board Fam Pract. 1992;5(4):419-24.

59. Mostow C, Principal investigator; Gordon S, Co-principal investigator Precepting for Cultural Competence. BCBSM Medical Foundation 2004-5.

60. www.aachonline.org Accessed January 2010.

61. Campinha-Bacote J. The process of cultural competence in the delivery of healthcare services: a model of care. J Transcult Nurs. 2002 Jul; 13 (3): 181-4; 200-1.

62. Jones C. Confronting Institutionalized Racism. Phylon 2002 (1960-) 50 (1/2):7-22 Also available at http://www.jstor.org/stable/4149999

63. Stern DT. In search of the informal curriculum: when and where professional values are taught. Acad Med. 1998;73(suppl 20):S38-30.

64. Suchman AL, Williamson PR, Litzelman DK, et al. The Relationshipcentered discovery team: toward an informal curriculum that teaches professionalism: transforming the social environment of a medical school. J Gen Intern Med. 2004;19(5 pt2):501-4.

65. Snyder L, Leffler C, Ethics and Human Rights Committee, American College of Physicians. Ethics Manual, 5th ed. Ann Intern Med. 2005; 142:560-82. 